ISBN 978-93-84468-86-6

2016 International Research Conference on Social Sciences, Humanities and Interdisciplinary Studies

(RCSSHIS-2016)

Pattaya (Thailand) Dec. 16-17, 2016

\title{
The Investigation of the Effect of the Bullying Prevention Program
}

\author{
Mustafa Eşkisu ${ }^{1,2}$, Sedat Gelibolu ${ }^{1}$, and Metin Pişkin ${ }^{1}$ \\ ${ }^{1}$ Ankara University, Faculty of Educational Sciences, Ankara, Turkey. \\ ${ }^{2}$ Corresponding author: Tel: +90 5321659025 Ankara University, Faculty of Educational Sciences, Ankara, \\ Turkey.
}

\begin{abstract}
Bullying is a common behavioral problem in schools, especially in the primary and middle schools. It effects the individual development of students and additionally the whole educational process. When the effects of bullying are considered, prevention programs gain more importance. The purpose of this study is to assess the effectiveness of Bullying Prevention Program. A pre/posttest, semi-experimental research design was used for this study. Thirteen middle schools in Turkey implemented the program based on the whole school approach. Using the Peer Bullying-Victimization Scale, data were gathered from 1703 students. In the post test, the mean scores of some subscales of the Peer Bullying-Victimization Scale were significantly lower than in the pre-test. The results of this study show that the Bullying Prevention Program is effective in decreasing some dimensions of the bullying and victimization.
\end{abstract}

Keywords: Bullying, victimization, bullying prevention program

\section{Introduction}

Bullying, a kind of aggressive behavior, is the repeated, intentional and harmful behaviors of one or more people against to weaker students [1]. Early studies about bullying go back to the Olweus' pioneering works in the 1970's in Scandinavia and spread over other countries thereafter. The definition was also diversified by many researchers; Besag [2] for instance, explains bullying as repeating physical, psychological, social or verbal attacks from the more powerful students to the ones who are not able to countervail. Sharp and Smith [3], put a more detailed definition, that is; bullying is sort of behaviors done by a student to a chosen victim student, such as verbally disturb, push and shove, spurn, threaten, immure in and never talk to. Considering these several definitions, the three common criteria can be mentioned for bullying. First; it should be a deliberate harm and misbehavior, second; it shouldn't be temporary and momentary, and the last one there should be an imbalance of power between bully and victim [4].

The prevalence of school bullying depends on which question is asked and its assessment, hence when students are asked whether they have ever felt they have been treated badly by another chil ${ }^{1} \mathrm{~d}$, the rate of positive answers can approach 100 per cent but can go down to 5 per cent if they are asked about bodily harm [5]. Within this range researches show variable rates for students to have been bullied or being bullies. Studies conducted in different countries demonstrate prevalence ranging between 8 to $46 \%$ for being bullied and 5 to $30 \%$ for active 
bullies [6]. Nevertheless bullying is a phenomenon that excessive emphasis should be put on especially in the school settings.

When students suffer from bullying, results can be vary from depression to the committing suicide as the most attention-grabbing level. Three boys' suicide in Norway in 1983 led to first major anti-bullying intervention in schools. After that there have been many intervention programs developed and implemented in order to counter bullying in the rest of the world. Despite a great variety of programs there has been a common feature that countering bullying requires a "whole school approach" in which the elements and participants in the program should carefully be coordinated. Therefore, it can be said that the effectiveness of the program may rely on the success of involving the whole school in the program. The success of intervention programs sometimes is questionable since some researchers have reported that on average the numerous interventions have been ineffective; others point to small reductions less than 20 per cent [7], [5]. By taking into account this point, the main purpose of this study is to examine the effectiveness of Bullying Prevention Program implemented in the thirteen middle schools in the capital city of Turkey, Ankara.

\section{Method}

\subsection{Participants}

Participants in this research are 1703 middle school students at 13 different state middle schools in Turkey. The sample was comprised of 859 girls and 844 boys, having 581 sixth graders, 558 seventh graders and 564 eight graders.

\subsection{Measures}

The bullying and victimization level was measured by the Peer Bullying- Scale-Adolescent Form. The scale, consisting of 53 items, has two dimensions (bullying and victimization) and 6 sub-factors and a total score. Higher score indicates higher level in bullying or victimization. The internal consistency of sub-factors varies between .80 and $.98[8]$.

We also created several additional bullying-related items in an attempt to define what students do when they are bullied and witness bullying, whom they share this information when they were bullied.

\subsection{Procedure}

Time-1 data were collected in the beginning of the academic year and Time- 2 data were collected in the end of the first semester. The Bullying Prevention Program was implemented by each school' school counsellors in all participating schools. This program was developed and implemented based on whole school approach. Before the program applications, all school counsellors were trained by the researchers. The program consists of informing meetings for teachers and parents, conferences for students and psycho-educational group programs for students who bully or be bullied. It aims to prevent and decrease the bullying incidents at school. Moreover, the other goals of the program are to train the victims to develop coping skills and to create awareness about bullying at the school setting.

\section{Results}

\subsection{The Effectiveness of Bullying Prevention Program}

T1 and T2 data were analyzed to examine the effectiveness of the Bullying Prevention Program. As seen in the Table I for victim dimension, T1 scores of the psychical, verbal, isolation, rumor spreading sub-factors and total victimization score are significantly lower than T2 scores. On the other hand, attacks on property, and sexual sub-factors' scores don't differ significantly between T1 and T2.

Regarding bullying dimension, T1 psychical, verbal, isolation, and rumor spreading sub-factors' scores are significantly lower than T2. But there is not any significant differentiation about attacks on property and total 
bullying scores. Moreover, on the contrary to our expectation, T1 score of the sexual bullying are higher than $\mathrm{T} 2$.

TABLE I: T-Test Result of the Pre-Test and Post-Test Scores of the Peer Bullying Scale

\begin{tabular}{|c|c|c|c|c|c|}
\hline Dimension & Sub-Factor & T1 Mean (sd) & T2 Mean (sd) & $\mathrm{t}(\mathrm{se})$ & $\mathrm{p}$ \\
\hline \multirow{7}{*}{ Victimization } & Psychical & $28,1(10,4)$ & $27,0(10,7)$ & $4,27(, 27)$ & ,000 \\
\hline & Verbal & $13,5(6,3)$ & $12,7(6,2)$ & $4,73(, 15)$ & 000 \\
\hline & Isolation & $9,4(4,7)$ & $9,0(4,6)$ & $3,46(, 12)$ & ,001 \\
\hline & Rumor spreading & $7,8(4,0)$ & $7,4(3,8)$ & $3,52(, 10)$ &, 000 \\
\hline & Attacks on property & $13,2(5,1)$ & $13,1(5,5)$ & $0,84(, 15)$ & ,400 \\
\hline & Sexual & $12,2(4,9)$ & $12,3(6,0)$ & $-0,82(, 15)$ & ,414 \\
\hline & Total & $84,2(28,4)$ & $81,6(30,9)$ & $3,57(, 74)$ & ,000 \\
\hline \multirow{7}{*}{ Bullying } & Psychical & $20,6(7,6)$ & $\begin{array}{l}20,0(8,3) \\
\end{array}$ & $2,2,24(, 23)$ & ,026 \\
\hline & Verbal & $9,3(3,8)$ & $9,0(4,0)$ & $3,33(, 11)$ &, 001 \\
\hline & Isolation & $7,4(2,84)$ & $7,2(3,2)$ & $2,04(, 09)$ & ,042 \\
\hline & Rumor spreading & $5,8(2,1)$ & $5,6(2,4)$ & $2,11(, 07)$ & ,035 \\
\hline & Attacks on property & $10,9(2,7)$ & $11,0(4,4)$ & $-1,31(, 12)$ & , 189 \\
\hline & Sexual & $10,7(2,5)$ & $11,0(4,6)$ & $-2,06(, 12)$ & ,040 \\
\hline & Total & $64,7(17,4)$ & $63,9(24,0)$ & $1,29(, 63)$ & ,198 \\
\hline
\end{tabular}

n: 1703

\section{Discussion}

The present study investigated the effectiveness of the Bullying Prevention Program on the prevention of bullying incidents at the school. As expected, we found that the scores of psychical, verbal, isolation, rumor spreading, and total victimization decreased significantly after the implementation of the Bullying Prevention Program. Psychical, verbal, isolation, and rumor spreading scales of bullying scores also decreased in the T2. A study, implemented in Turkey, found that a school bullying program was effective in decreasing all of the subscales of victimization and "threatening/intimidating" subscale of bullying [9]. Şahin, also found that empathy training was effective as an intervention program in prevention of bullying [10]. But we did not find any significant differentiation between pre-test and post-test scores on attacks on property and sexual in victimization and attacks on property and total bullying in bullying dimension. In the literature as our findings; there are some studies which have different results. Some reported significant program effects whereas some reported no significant effects and others reported mixed findings [11], [12]. However, it was revealed that bullying prevention programs are cost-effective when the effects of bullying is considered [13].

The interesting finding is that on the contrary to our expectation sexual bullying score increased after the implementation of The Bullying Prevention Program. These results may stem from the fact that the school counsellors in their intervention activities mainly focused on the physical, verbal, isolation, and rumor spreading, rather than attack on property, and sexual issues. On the other hand, the developmental pathway of the middle school adolescents may effect this increasing on sexual bullying.

\section{Conclusion}

The results indicated that the Bullying Prevention Program was influential in reducing both bullying and victimization level of the children. The program needs to be revised as to put more intense activities about attack on property and sexual bullying and victimization. 


\section{References}

[1] D. Olweus, Bullying at school. Oxford: Blackwell, 1995.

[2] V. E. Besag, Bullies and victims in schools: A guide to understanding and management, Open University Press, 1989

[3] S. Sharp and P. K. Smith, School bullying: Insights and perspectives, Routledge, 2002.

[4] D. Olweus, S. Limber and S. F. Mahalic, Bullying prevention program, Center for the Study and Prevention of Violence, Institute of Behavioral Science, University of Colorado at Boulder, 1999.

[5] K. Rigby, Bullying interventions in schools: Six basic approaches, Australian Council for Educational Research, 2010.

[6] M. Fekkes, F. I. Pijpers and S. P. Verloove-Vanhorick, "Bullying: Who does what, when and where? Involvement of children, teachers and parents in bullying behavior", Health Education Research, 20 (1), pp. 81-91, 2005. https://doi.org/10.1093/her/cyg100

[7] P. K. Smith, D. Pepler, K. Rigby, Bullying in schools: How successful can interventions be? Cambridge University Press, 2004. https://doi.org/10.1017/CBO9780511584466

[8] M. Pişkin and T. Ayas. Akran Zorbalığı Belirleme Ölçeği Ergen Formu (Peer Bullying Scale Adolescent Form). Akademik Baklş Dergisi, 50, pp. 316-324, 2015.

[9] S. Albayrak, A. Yıldiz and S. Erol. Assessing the effect of school bullying prevention programs on reducing bullying behaviors. Children and Youth Services Review, 63, 1-9, 2016.

https://doi.org/10.1016/j.childyouth.2016.02.005

[10] M. Şahin. An investigation into the efficiency of empathy training program on preventing bullying in primary schools. Children and Youth Services Review, 34, 1325-1330, 2012. https://doi.org/10.1016/j.childyouth.2012.03.013

[11] C. B. R. Evans, M. W. Fraser and K. L. Cotter. The effectiveness of school-based bullying prevention programs: A systematic review. Aggression and Violent Behavior, 19, 532-544, 2014.

https://doi.org/10.1016/j.avb.2014.07.004

[12] I. Zych, R. Ortega-Ruiz and R. D. Rey. Systematic review of theoretical studies on bullying and cyberbullying: facts, knowledge, prevention, and intervention. Aggression and Violent Behavior, 23, 1-21, 2015.

https://doi.org/10.1016/j.avb.2015.10.001

[13] L. Beckman and M. Svensson. The cost-effectiveness of the Olweus Bullying Prevention Program: Results from a modelling study. Journal of Adolescence, 45, 127-137, 2015. https://doi.org/10.1016/j.adolescence.2015.07.020 